\title{
UN CUERPO LLENA LA INMENSIDAD: LA PALABRA Y EL ESPACIO EN LA ESCULTURA DE JAUME PLENSA
}

\author{
Jordi MASSÓ CASTILLA \\ Universidad Complutense de Madrid \\ jsmasso@ucm.es \\ El lugar es la palabra \\ A. Silesius
}

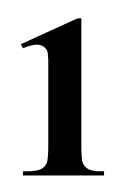

\section{Introducción}

Resulta cuando menos chocante la siguiente aseveración contenida en el ensayo El arte y el espacio de Martin Heidegger: «La pregunta de qué es el espacio en cuanto espacio no está planteada, y menos aún contestada. Queda por resolver el modo en que el espacio es y si se le puede atribuir en general un ser» (Heidegger, 1969a: 17). Extrañas palabras habida cuenta de que en el momento en el que el filósofo alemán escribe esas líneas - 1969-, eran abundantes sus escritos, conferencias y seminarios en los que se había preguntado de alguna manera por la esencia del «espacio». Sin ir más lejos, cinco años antes Heidegger había leído un breve ensayo con motivo de la inauguración de una exposición dedicada a la obra del escultor Bernhard Heiliger. En este texto, titulado Observaciones relativas al arte - la plástica - el espacio, el pensador, tras hacerse la misma pregunta — «qué es el espacio?»— recoge las principales respuestas que el pensamiento occidental ha ofrecido a tal cuestión. Aristóteles, Galileo y Kant, con sus respectivas teorías sobre el espacio (el espacio como lugar, como dimensión tridimensional, como modo de representación de los objetos), son entonces mencionados. Sin embargo, ninguna de ellas llega siquiera a rozar el corazón del problema, quizás porque como acabamos de leer, la pregunta por el espacio no ha encontrado aún una formulación adecuada. Tampoco sirven, puede colegirse de lo anterior, las reflexiones del propio Heidegger anteriores a 1969, esto es, las de prácticamente toda su obra.

Lo que aquí nos interesa no es exponer o analizar la cuestión del espacio en la filosofía heideggeriana. Si se ha traído a colación la obra de este filósofo es porque los dos ensayos citados ofrecen pese a todo, pese a esa insistencia en que el espacio resta un 'impensado' en la filosofía occidental, una respuesta a la pregunta por su esencia. Contestación elíptica, si se quiere, pero nítida al situar en el ámbito de las artes y de la Estética la dilucidación de la cuestión. Concretamente, es la escultura - la de Heiliger, en el ensayo de 1964; la de Eduardo Chillida, en el de 1969- la que va a desvelar, cómo si no, la verdad del espacio. Y es en este punto en donde la obra de Jaume Plensa se 
antoja la continuación de la reflexión de Heidegger allí donde éste la dejó sin llegar a atisbar lo que las esculturas de este artista muestran: que el espacio es ante todo el que abren los cuerpos y que las piezas escultóricas son textos que demandan un tipo de lectura en el que participan todos los sentidos.

Regresemos un momento a los dos escritos de Heidegger. Allí, decíamos, puede hallarse una tentativa de dar repuesta a la pregunta por el espacio. Lo más destacable de la propuesta del filósofo es que toma como referencias a dos momentos de la tradición filosófica tan alejados entre sí como lo están el pensamiento griego, personalizado en Aristóteles, y el Romanticismo. La presencia de este último, por cierto, es constante en los trabajos de Plensa, en sus esculturas grabados y escritos, como enseguida expondremos. ¿Por qué Aristóteles? ¿Por qué el Romanticismo? El filósofo griego, explica Heidegger, designó a lo que el hombre moderno entiende por «espacio» con dos términos: topos [ $\tau$ бos] y chora $[\chi \omega ́ \rho \alpha]$. Así como el primero alude al espacio «que un cuerpo inmediatamente ocupa» y que comparte con éste «los mismos límites», chora «mienta el espacio, en la medida en que éste puede acoger y abarcar tales lugares» (Heidegger, 1969b: 77). Retengamos esta caracterización del espacio como aquello que acoge y que comprende los lugares, una concepción alejada de la que ha prevalecido en Occidente, más cercana a la del topos. Lo que Heidegger se propone es recuperar de algún modo la chora aristotélica, que sin duda remite a la platónica ${ }^{1}$, para poder pensar en adelante lo espacial como lo que permite la disposición de los cuerpos. Ya no se trata del espacio físico ocupado por éstos, sino del espaciamiento gracias al cual hay lugares, siempre definidos a partir de las posiciones que ocupan los cuerpos.

Por lo que respecta al otro referente, el Romanticismo, Heidegger no lo menciona explícitamente, pero sin duda alguna es lo que sobrevuela una reflexión de su ensayo de 1964. El argumento se desarrolla en el cuerpo del texto, pero sólo alcanza toda su dimensión cuando es completado por una nota que añade el filósofo. Reproduzco a continuación el fragmento, seguido entre corchetes por el contenido de ese añadido:

[...] qué sean las artes figurativas, qué el arte en cuanto tal es cosa que no se deja determinar ni exponer con ayuda del cincel y el martillo, o por medio del color, con el pincel, ni a través de la obra producida con ayuda de esos instrumentos. El arte en cuanto tal no es ningún tema posible de la figuración artística. [Sino de la poesía - del poeta] (Heidegger, 1969b: 69).

De nuevo una pregunta. Parece, entonces, como si algo ligase la interrogación por la esencia del 'espacio' con la búsqueda de la esencia del 'arte'. Pero así como Heidegger se aventura a proporcionar unas indicaciones que permiten retomar la meditación griega sobre el espacio, interrumpida según él por el dominio de la metafísica occidental, en el caso del arte no se atreve a hacerse cargo de semejante reflexión. Únicamente los poetas pueden determinar qué es el arte «en cuanto tal». La preeminencia de la poesía [Dichtung] sobre las demás es una de las herencias del Romanticismo que Heidegger recibe sin cuestionarse. Es más, en otro de sus escritos más célebres, la conferencia El origen de la

\footnotetext{
${ }^{1}$ Ana María Leyra proporciona una clara descripción de este concepto que se halla en el diálogo Timeo: «la noción de Chora, en Platón, califica, nombra un espacio matricial, que no es propiamente un espacio físico. No se trata del espacio de los cuerpos, ya que para este espacio los griegos utilizaban otra palabra: topos, sino que se trata del ámbito de lo virtual, de lo que todavía no es pero hace posible que algo sea» (Leyra, 2014: 166).
} 
obra de arte, este pensador defendía la idea de que «todo arte es en su esencia poema» (Heidegger, 1984: 52), si se entiende por tal un 'decir' que permite el «desocultamiento» de lo ente. La escultura, toda escultura, ya sea la de Chillida, la de Heiliger o la de Plensa han de ser pensadas como poemas, esto es, como desveladoras de la verdad de lo existente. Por tanto, no tiene nada de casual que en dos escritos en los que el filósofo lanza la pregunta por la esencia del espacio aparezca la idea romántica del artista como poeta, dando a entender que tal vez la respuesta e incluso la formulación adecuada de la cuestión estén en manos de esos escultores, Chillida y Heiliger, en su caso.

Si lo anterior es cierto, no hay un modo mejor para conocer qué es el espacio que acercarse a las piezas de aquellos artistas a los que Heidegger prestó su atención. Quien haya estado ante una obra de Chillida puede dar fe de cómo en esa experiencia se descubre la esencia de lo espacial, que sin embargo es muy difícil, por no decir imposible, traducir en palabras; puede testimoniar cómo gracias a esa creación se tiene una percepción única del espacio. Los trabajos de Jaume Plensa suscitan con un lenguaje diferente una reflexión similar, y no sólo porque en ellos haya también algo de la chora aristotélica y del 'Decir' romántico, sino porque también «desocultan» la verdad del espacio, su esencia, un rasgo que podrían compartir las creaciones de un sinfín de artistas (Jorge Oteiza, Richard Serra, Cristina Iglesias, Susana Solano...). La originalidad de Plensa se halla en la manera en la que vincula la espacialidad con la corporeidad y con la escritura. Y en esto es, creemos, un artista pionero. Veámoslo con detenimiento.

\section{La medida de las palabras}

En una de las notas a la traducción de Observaciones relativas al arte - la plástica - el espacio Félix Duque recuerda, remitiéndose a la Física aristotélica, que «chôra está emparentada con cháos: en sentido primordial, "lo Abierto" que, por ende, mantiene las distancias entre los entes» (Heidegger, 1969b: 101). Ese espacio primigenio o, mejor dicho, ese espaciamiento gracias al cual hay lugares físicos que pueden ser ocupados por cuerpos, tiene pues mucho de caótico, esto es, de dis-posición previa a cualquier emplazamiento. De este modo, el Caos, más que el origen, es lo que asegura que haya un espacio en el que puede haber lugares y cuerpos. Estaría, pues, próximo a la noción heideggeriana de «lo Abierto». En otras palabras, vendría a ser ese claro de ser gracias al cual puede haber manifestación o desocultamiento de los entes. Por eso más arriba decíamos que el Caos, chora, no es el origen del espacio - o el espacio como origen-, sino más bien el sustrato que hace posible la espacialidad, que haya lugares ocupados por cuerpos. Caos es la materia con la que están hechos los lugares abiertos por la escultura.

Chaos-Saliva es el título de una pieza de 1999 compuesta por dos gongs de bronce suspendidos. En cada uno de ellos está grabada una de esas palabras: chaos, saliva. Dice al respecto Plensa: «el caos queda instantáneamente unido a la saliva, ese lubricante que genera nuestro cuerpo para que en la boca puedan suceder desde las cosas más bellas a las más trágicas» (Plensa, 2000: 62). Boca, recuerda el filósofo Jean-Luc Nancy, proviene de 'bucca'. A diferencia de la boca de la oralidad, denominada en 
latín 'os, oris', 'bucca' es «el movimiento, la contracción y/o la distensión de soplar, del comer, del escupir o del hablar. La bucalidad es más primitiva que la oralidad. Nada ha tenido lugar allí todavía, y sobre todo nada ha hablado de antemano» (Nancy, 1979: 162). ¿Cómo de «primitiva» es esta boca? Igual de primitiva que el caos, de esa dis-posición o de ese espaciamiento hay cuerpos y hay lugares. La saliva, explica el escultor, es la sustancia que cubre esa especie de caverna que es el orificio bucal; es la materia con la que están hechas las cosas que «suceden» en la boca. Y todo puede ocurrir allí porque es el origen de la palabra, del lenguaje, con el que se puede representar todo cuanto existe, desde lo más íntimo a lo más externo.

Habíamos señalado que cada uno de los discos de la escultura tiene grabada una palabra. Falta añadir que junto a ellos cuelga un mazo con el que el espectador puede golpearlos. La sonoridad que producen el chaos y la saliva es la de unas palabras que aún no han sido articuladas por una boca, 'os, oris', pero que ya pueden escucharse en y como una 'bucca'. Las vibraciones de los gongs sería el de un lenguaje compuesto por esos «movimientos» de los que habla Nancy y en los que las palabras permanecen en estado latente: «Entro en tu boca para dormir con las palabras», reza un verso de un poema de Plensa (Plensa, 2000: 118). Otro tanto podría decirse de una pieza próxima en el tiempo, 13 doubts, que consta de trece campanas tubulares que invitan a ser golpeadas, mejor dicho, escuchadas, con la ayuda de un martillo. Las medida de cada cilindro es diferente, lo que unido al hecho de que la palabra que cada uno lleva inscrita también lo sea, produce siempre un sonido particular. No hay uniformidad sonora posible, por tanto. La instalación emite una polifonía de palabras que tiene mucho, inevitablemente, de caótica, esto es, de espacio originario anterior a cualquier articulación.

Pero para llegar al chaos de las palabras, a su sustancia sonora y vibrátil, fue necesario un camino de búsqueda y de tanteos. Lo que Plensa ya perseguía en sus trabajos de finales de los años ochenta era hallar una nueva materia que aunase lenguaje, palabra, y corporeidad. Baudelaire (1989) o Déluge (1990) podrían considerarse una primera tentativa. Cada una de estas piezas consta de un colosal cilindro de hierro. En la primera, un poema de Baudelaire recubre su exterior; en la otra, una oquedad permite adentrarse en su interior para descubrir en las paredes un fragmento bíblico. La elección de estos escritos nada tiene de casual. Baudelaire es uno de los poetas malditos por excelencia, autor de una «letanía de Satán» en la que ora al ángel caído. Si el Romanticismo fue la época que constató que los dioses han huido y, por ello, faltan nombres sagrados, como dejó escrito Hölderlin, el poeta francés tomó el testigo para dirigirse directamente al «más sabio y más hermoso» de los ángeles y pedirle piedad, a él, el único que puede escucharle en esos tiempos de miseria por la ausencia de lo divino. En cuanto al diluvio, es uno de los relatos bíblicos más antiguos, uno de los grandes mitos fundacionales de las religiones del Libro.

La empresa que es esa búsqueda de una nueva materia a cargo de Plensa tenía, pues, mucho de mito y de poesía. El artista se siente como el poeta que de nuevo tiene que poner nombre a lo existente sin poder apelar a dios alguno. «Muchas de mis obras son pequeños homenajes a la actitud del poeta ante las cosas», ha reconocido (Plensa, 2005: 15). Esa nominación se convierte así en un acto creador que es posible, que es dis-puesto, por el silencio de lo sagrado: 
[...] en la palabra poética se expresa que los seres se callan. ¿Pero cómo ocurre esto? Los seres se callan, pero entonces el ser tiende a convertirse en palabra y la palabra quiere ser. La palabra poética ya no es palabra de una persona: en ella nadie habla y lo que habla no es nadie, pero parece que la palabra sola se habla (Blanchot, 1955: 35).

«La palabra quiere ser», nos dice Blanchot. ¿Sería la escultura de Plensa un intento por dotar al lenguaje de ser? Tal es, como sabemos, la tarea que ha asumido el arte desde el Romanticismo. Antes comentamos cómo para Heidegger todo arte remite a la poesía en cuanto 'Decir' desvelador de la esencia de lo ente. Pero esto sólo es posible porque los dioses o lo Sagrado han huido: «espaciar es libre donación de los lugares en los que aparece un dios, de los lugares de los que los dioses han huido, lugares en los que el aparecer de lo divino se demora mucho tiempo» (Heidegger, 1969a: 23). Ese «espaciar» no es sino la tarea del escultor. A la ausencia de nombres divinos responde el artista con su obra, procedente del silencio y que toma la forma de la palabra. Eso incluye también a quien trabaja con volúmenes, con espacios, que se tornan así, también ellos, lenguaje. A propósito de su célebre The Crown Fountain (2004), instalada en el Millenium Park de Chicago, Plensa reflexiona: «yo quería recuperar esta idea en el espacio público actual, pero utilizando a la propia gente que vive en la ciudad como mitología. Ya no es necesario buscar a dioses, los dioses somos nosotros y es la gente anónima la que hace crecer una ciudad, le da tono y carácter» (Plensa, 2005: 21). ¿Podría haber un reconocimiento más tácito del romanticismo que late en la obra de Plensa? Esta huella, apenas señalada en los estudios dedicados al artista, es, creemos, fundamental para comprender su trabajo con la escritura y con la imagen, con las esculturas en las que se inscriben textos. No hay dioses, sostiene este creador, y por eso debe ser él quien cree una nueva mitología 2 .

La pregunta sigue siendo con qué construir esa mitología, ese espaciamiento gracias al cual las palabras van a(1) ser. Plensa considera decisiva a este respecto una de sus piezas, Sleep no more (1988), inspirada en la obra de otro poeta, el Macbeth de Shakespeare. En esta obra, explica el artista, «por fin las palabras [...] tomaron la sustancia física de la medida y el peso» (Rendueles, 2007: 44). Se trata de la primera obra en la que introdujo un texto, en este caso destacado en relieve sobre una plancha de hierro, encima de la cual se yerguen tres bloques superpuestos; en el último, el superior, se observan tres oquedades con forma semiesférica. Ese «por fin» da idea de que el hallazgo ponía fin a un proceso y a una búsqueda, la de cómo materializar las palabras. Si se presta atención a las palabras de Plensa, resulta significativo que aquello de lo que están compuestos los textos de esta pieza, a la que cabría añadir Baudelaire y Déluge, no sea el hierro, como resulta obvio en un primer acercamiento. No, no se trata de este material, empleado por el artista en una década, la de los ochenta, marcada por su interés por la aplicación de técnicas industriales a la escultura (Stoeber, 2006: 41), lo que por cierto lo sitúa en la estela de los grandes escultores españoles del siglo XX, Chillida y Oteiza. Tampoco lo será

\footnotetext{
${ }^{2}$ La creación de una nueva mitología, «de la razón», era, recuérdese, uno de los puntos fundamentales de El programa de sistema más antiguo del idealismo alemán, el texto escrito probablemente por Hölderlin, aunque con la ayuda de Hegel y de Schelling.
} 
la luz, introducida en la década siguiente en esculturas que constan de una placa de hierro en la que está inscrito un texto y en cuyo centro se sitúa un foco que proyecta una vertical luminosa ${ }^{3}$. Ni hierro, ni luz, ni vidrio, ni resina de poliéster —que hará su aparición un poco más tarde-: las esculturas de Plensa están hechas de «medida» y de «peso».

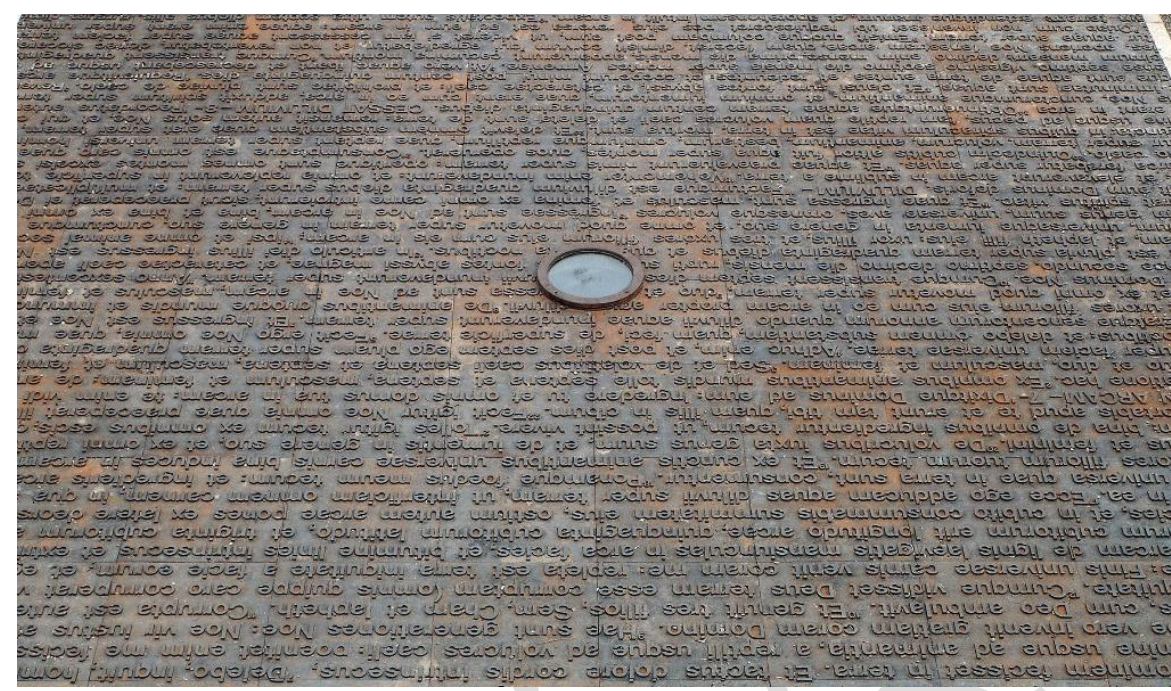

Fig. 1: Auch (detalle), 1991. Hierro y luz, 5 x 1000 x $1000 \mathrm{~cm}$. Escalier Monumentale. Auch, Francia. Foto Leopold Samsó @ Plensa Studio Barcelona.

La «medida» remite de nuevo al espacio poético, ámbito que en realidad la obra de Plensa jamás abandona. Leemos en uno de sus poemas fechado en 1990: «Obstruir la entrada. Cerrar el espacio. Bloquear la puerta. / Establecer una medida entre las paredes y nosotros. / Volverse lento, muy lento, tres veces más lento. / Subir a lo alto y contemplar los huecos, los pasillos, los abismos. / La medida bloqueada en la memoria de nuestra bárbara escritura» (Plensa, 2000: 114). Cómo no pensar, tras estas palabras, en el poeta de la medida exacta y del cálculo, Hölderlin. En sus abigarrados escritos teóricos es reiterativa la idea de que la creación poética es ante todo una tarea que exige calcular con precisión. De este modo:

La obra no es una medida dada con la que el poeta sometería a lo inconmensurable, como un yugo y una limitación. Sin embargo, la medida que es la obra permite calcular la relación de lo incalculable (del sentido) con una pequeña apertura de palabras. En cierto modo, se trata siempre de un cálculo infinitesimal, el cálculo de un punto exacto de fuga o de tangencia: la coincidencia del sentido incalculable con una breve expresión (Nancy, 1997: 89).

¿Y qué es lo que así se mide? Lo divino, es decir, lo ausente y que por ello es inconmensurable. «El Dios o los dioses - explica Félix Duque- son en efecto la revelación, en cada caso distinta, de lo Sagrado. Dan la medida a los hombres porque ellos proceden de lo que no es susceptible de medida (Unmessbar)» (Duque, 2006: 15; cursiva en el texto). El poeta, el artista, se empeña en establecer una medida con la que acceder a eso Sagrado. Plensa hace suya esta meta, que en su caso se convierte en el esfuerzo por desbloquear la medida que se halla «en la memoria de nuestra bárbara escritura». Las palabras, según él, están encerradas en «la prisión de la página». Y todas ellas son «como cualquier material, un gran contenedor de memoria y es en este aspecto como lo utilizo, no para ser leída o para ilustrar, sino más bien como una presencia, la presencia de la palabra tanto visual como sonora, sin necesidad de ser leída o pronunciada» (Plensa, 2000: 59).

\footnotetext{
${ }^{3}$ Entre estas obras sobresalen Auch ([Fig. 1] 1991, con el pasaje del Antiguo Testamento sobre el Diluvio universal) y Blake in Gateshead (1996, con el «proverbio del infierno» de William Blake «No bird soars too high if he soars with his own wings» [Ningún pájaro puede volar alto si sólo vuela con sus propias alas]).
} 


\section{El peso de las palabras}

Recapitulemos. Las palabras tienen presencia en las obras de Plensa por su materialidad, entendida ésta como «medida» y «peso». El primer rasgo significa que los textos que el espectador encuentra en las piezas del artista han sido rescatados del soporte de la página para ser ubicados en un ámbito en el que adquieren nuevas características: espacialidad, sonoridad, tangibilidad. Sigue siendo escritura, sí, pero escritura de los cuerpos, de los cuerpos en cuanto lugares. Pronto nos ocuparemos de ello. Hay que insistir antes en ese otro elemento fundamental en la escultura de Plensa: la memoria. Las palabras deben despertar el recuerdo individual del espectador. «El hierro, la resina, la luz, la palabra: muchos vehículos, contenedores, que me permiten buscar un punto común en la memoria. ¿Una memoria literaria? No, una memoria escrita, abierta a sus errores y posibles malentendidos» (Plensa, 1997: 43). Cada una de las 38 puertas de Wonderland II (1997) lleva en relieve una palabra: 'fish' [pescado], 'bread' [pan], 'cheese' [queso]... términos cotidianos que fácilmente hace suyos quien los lee. A cualquiera le ‘dicen' algo estas palabras, y por ello Plensa apela a este espacio común compartido por todo sujeto, artista y público. Actuarían, pues, como una especie de dispositivo que activa la memoria del receptor. De esta manera, las obras de este artista configuran una chora compuesta de palabras en la que éstas son también sonidos, extensiones, saliva. Y, sobre todo, recuerdos, ideas: pensamiento.

Hans-Jürgen Buderer destaca atinadamente cómo Plensa se proponer «realizar la transformación del pensamiento indefinido que emerge de un interior disimulado hasta concretarse en palabras, inscritas en la superficie de la escultura» (Buderer, 1997: 33). Ese pensamiento indefinido bien podría ser esa chora compartida desde la que se originan las palabras. De este modo, el lugar propio de los textos de las piezas de Plensa es el del pensamiento, un dominio atravesado por la sonoridad que ya nos es conocida, pero también de silencio. Esto no apunta hacia un oxímoron ni tampoco hacia una paradoja. El silencio rodea las obras de Plensa; es, diríamos, el espaciamiento o la dis-posición que las acoge, el medio en el que son. Así se explica la fascinación que siente hacia los Proverbios del infierno de William Blake y, sobre todo, hacia uno de ellos: «One thought fills immensity» [un pensamiento llena la inmensidad]. Esto no significa, puntualiza Félix Duque,

[...] que un pensamiento llene la inmensidad, como si ésta fuera algo existente de antemano, sólo que vacío: como si se tratara de un recipiente, de una forma indefinida que ahora toma figura y hechura al ser llenada por el pensamiento. No. Un pensamiento colma inmensidad en el sentido de que él la instaura por vez primera, al desbaratar toda medida exacta, permanente, cósica (Duque, 2007: 143; cursiva en el texto).

No obstante, a esta reflexión le falta un elemento. Es necesario añadir la consideración de que para Plensa el pensamiento es «uno más de nuestros ruidos corporales». De lo que se trata entonces es de dar forma a esta materia aparentemente incorpórea, intangible, callada, y ello sin acudir al recurso más obvio: la verbalización de los pensamientos, su transformación en palabras. La vía elegida por el artista es la de mostrar que el ámbito del pensamiento es un espacio sonoro, permitiendo experimentarlo. El silencio en el que se produce esta percepción se corresponde así con el ruido que reina en el mundo de las ideas, de tal modo que estos dos dominios, el de lo sensible y el de lo 
inteligible, se dan la mano en las piezas de Plensa. Es éste el reino de las palabras, de los sonidos y de los silencios, unidos por compartir un mismo origen. «La palabra es un sonido que existe aunque no lo pronunciemos» (Plensa, 2000: 60). Los textos de las esculturas de Plensa suenan, aunque sólo se escuche el silencio, pues aún no han sido pronunciados y permanezcan en la boca en ese estado previo a la articulación. No obstante, siempre se puede percutir los gongs, que vibran como lo hacen los discos de bronce de Wispern (1999) [fig. 2] cuando una gota de agua cae sobre su superficie, en la que está grabado uno de los Proverbios del infierno de William Blake. Así se genera un ruido «como único puente entre el sonido y el silencio» (Plensa, 2000: 130), el mismo ruido que, como acabamos de ver, es propio del pensamiento.

«One thought fills immensity». El proverbio, en uno de los discos de Wispern, es uno de los hilos conductores de la trayectoria de Plensa. Ya

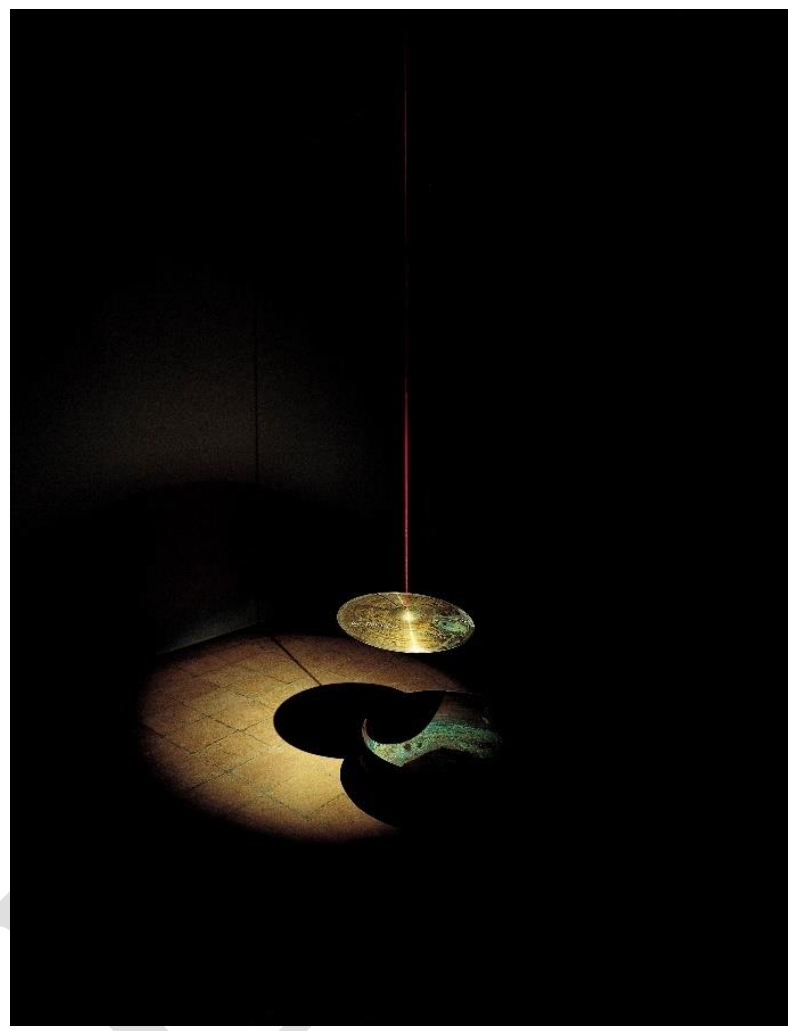

Fig. 2: One Thought Fills Inmensity, Wispern, 1997 (detalle). Bronce, cobre, cuerda y agua. Fattoria di Celle; Gori Collection; Santomato di Pistoia. Italia. Foto: Carlo Chiavacci (C Plensa Studio Barcelona. conocemos que la sustancia de este pensamiento es ruido, el mismo en el que se encuentran, en estado latente, las palabras que no han sido pronunciadas y que encuentran ahí su «medida». Pero también vimos cómo éstas, las palabras, pero también los pensamientos, son «peso». Tanto el 'pesar' como el 'pensar' provienen del término latino 'pensare': pesar, apreciar, evaluar. «El acto del pensamiento es un pesaje efectivo: el propio pesaje del mundo, de las cosas, de lo real en cuanto sentido», recuerda un autor que antes había asomado por estas páginas, Jean-Luc Nancy (Nancy, 1991: 3). El pensamiento pesa las cosas, las valora; las mide. Medida y peso son así indisolubles. Son, afirma Plensa, la «sustancia física de las cosas» en cuanto que éstas son pensamiento y memoria.

Antes señalábamos cómo el empleo que hace Plensa de materiales como el hierro lo sitúan en la tradición escultórica española del siglo XX. La contundente presencia de los volúmenes de sus piezas no se explica, empero, remitiendo a unos cuantos referentes. Hay algo más. Se trata, ahora lo sabemos, de la voluntad de transmitir una sensación de pesadez, de rotundidad, propia del espacio - caos y saliva - del pensamiento. Las palabras tienen peso — son físicamente poderosas - y medida — su medio es el ruido de las palabras y del silencio ${ }^{4}$ - Esta es, creemos, la clave de la relación entre escritura e imagen en la obra de este escultor y poeta, si se nos permite el pleonasmo, pues alguien que

\footnotetext{
${ }^{4}$ Señala con tino Ángel Gabilondo que las instalaciones de Plensa demandan una nueva mirada unida a una forma de escuchar inédita, las cuales se traducen en un «hacerse cargo de un nuevo silencio, no aquél en el que ya no hay palabras, sino en el que éstas acallan los ruidos habituales y retorna una miríada de sucesos por venir» (Gabilondo, 2007: 154).
} 
anhela hallar el lenguaje del pensamiento está condenado a encontrarse con la poesía, como ya advirtiera Maurice Blanchot: «entonces estamos tentados de decir que el lenguaje del pensamiento es por excelencia lenguaje poético, y que el sentido, la noción pura, la idea, deben convertirse en la preocupación del poeta, siendo esto lo único que nos libere del peso de las cosas» (Blanchot, 1955: 33).

\section{Cuerpo y caos}

Henos aquí ante unas esculturas, una «fuente de energía, de vibración, que emana de las cosas expandiéndose en espacio» (Plensa, 2000: 56). Esta es la verdadera materia de estas piezas, la chora de la que venimos ocupándonos de la mano de este artista. Más que liberarnos «del peso de las cosas», como querría Blanchot, a lo que invita esta creación, esta poesía, es a descubrir qué hace que pesen: el pensamiento. Al espectador le sucede entonces lo mismo que al lector, según describía Edmond Jabès: «en el momento de comenzar un libro - y sin duda no sea el único- me encuentro literalmente sumergido por su materia» (Jabès, 1980: 65). En la serie Curtains, textos de la Declaración de los Derechos Humanos (Glückauf?, 2004) o del Cantar de los cantares (Song of songs, 2005), cuelgan del techo de la sala en forma de tiras que contienen sus palabras. La escritura envuelve literalmente al espectador, quien, al adentrarse en estas cortinas textuales escucha el sonido que produce el choque entre las letras, hechas de hierro. Aunque siempre puedan ser leídos, el propósito de Plensa no es propiciar una lectura sino más bien una experiencia sensorial a través de la cual los textos tocan al espectador, rozando su piel, adentrándose en sus oídos en forma de tintineo metálico.

Silent rain (2003) reúne ocho de estas cortinas con textos de algunos de los poetas favoritos del artista (Goethe, Baudelaire, William Carlos Williams o Vicent André Estellés, entre otros). El título alude a la semejanza que guardan las palabras de la pieza con unas gotas de lluvia. También las letras empapan a quien se encuentre debajo de ellas con ese silencio que como bien sabemos no es sino ruido, el del pensamiento. Las palabras de Plensa han ido así aproximándose al cuerpo del espectador, quien ya no sólo las ve y las escucha, sino que también las toca. Lo siguiente debería ser la transformación de la piel humana en la superficie en la que se grabarían aquéllas, como si de un tatuaje se tratase, cumpliendo así aquel viejo propósito de liberar las letras «de la prisión de las páginas».

Una buena conocedora de la obra de Plensa, Doris von Drathen, sostiene que «en las esculturas de los años 2005 y 2006 es en donde el artista ha hecho por primera vez que la lengua se independice de todo mensaje intelectual aprehensible, empleándola como un simple caos de letras» (Von Drathen, 2006: 25). Se refiere esta autora a los trabajos de Plensa realizados aproximadamente en esas fechas y en los que el espectador tiene ante sí una escultura de forma humana, siempre en la misma postura — sentada, abrazando sus piernas-, y cuya piel es un tejido de letras. En ocasiones el trazado del cuerpo - su escritura - parece haber sido dejado a medias (Tel Aviv Man I, 2003); otras veces lo único que falta es el rostro (Nomade, 2007; Spiegel, 2010 [fig. 3]), abundando así en el carácter anónimo de 


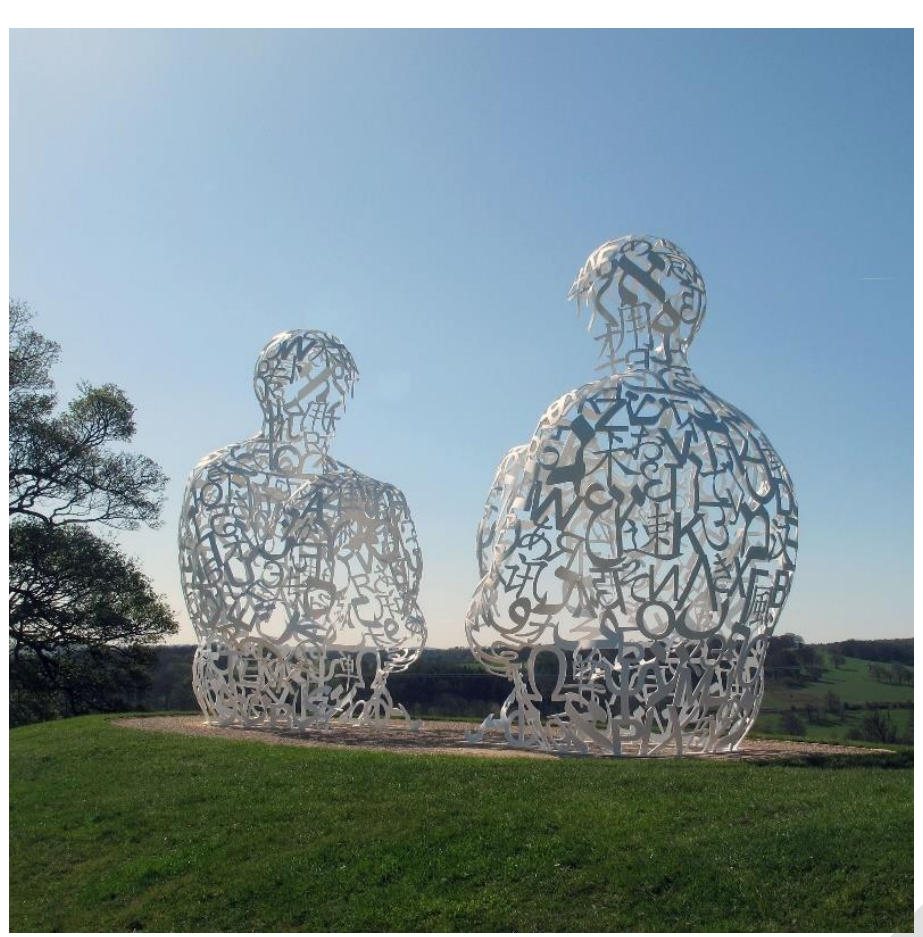

Fig. 3: Spiegel I y II, 2010. Acero inoxidable pintado, 377 x 235 x $245 \mathrm{~cm}$ cada elemento. Vista de la instalación Jaume Plensa. Yorkshire Sculpture Park, West Bretton. UK 2011. Foto Laura Medina (C) Plensa Studio Barcelona.

estos cuerpos, de estos textos. Y es que no existe un término para referirse a esta escritura corporal que propone Plensa, tal vez porque a falta de nombres sagrados, son precisamente estas esculturas las que proponen una nueva denominación hecha de palabras aún sin articular.

Las letras que forman estos cuerpos suelen permitir ver el interior ${ }^{5}$ : una oquedad que, sin embargo, no alberga un vacío sino un espacio. Por eso estas palabras no contienen un interior: dis-ponen un espacio, chora, el de las palabras, el del pensamiento. No se trata de que las letras que delimitan los cuerpos aboquen a una lectura imposible, de donde resultaría ese «caos» mencionado por Doris von Drathen ${ }^{6}$. Es cierto que esta escritura corporal no demanda la lectura usual con la que nos enfrentamos a los textos. Si es esto lo que se busca, leer estas esculturas, se errará, pues lo que ofrecen es un «caos», sí, pero entendiéndolo no como una amalgama de letras sin orden alguno, sino como ese espacio en el que las letras son aún pensamientos que aguardan ser proferidos. Plensa ha titulado alguna de estas piezas Tattoos [tatuajes], influido según confiesa por el judaísmo. «La cultura judía se basa en la palabra, en un punto, en una coma. Mueves una coma de sitio y cambia el sentido de todo, del mundo, del universo» (Plensa, 2005: 25). Esta religión es también, no debe olvidarse, la de la cábala, la del «libro absoluto que excluyese el azar; libro de la perfecta legibilidad» (Jabès, 1980 : 110). La escritura corporal o el cuerpo escritural, como se prefiera, que son estas esculturas, comparte este propósito 'demencial' — por superar los límites de la razón humana, del logos — de aspirar al libro infinito, que también anhelaron el romántico F. Schegel o Mallarmé.

De algún modo, tal vez en potencia, los cuerpos de Plensa contienen, mejor dicho, dis-ponen, todas las palabras de la humanidad. Son por ello el espaciamiento que dará lugar a todos los vocabularios que han existido y a los que están por surgir. Es, digámoslo una vez más, el chaos del lenguaje previo a su encierro en la página, cuando aún la palabra puede escucharse, tocarse, leerse...

\footnotetext{
${ }^{5}$ Hay excepciones a esta regla: Tattoo I (2003), The Three Graces I, II y IV (2005) o Doors of Jerusalem I, II y III (2006), esculturas de resina de poliuretano opaca o traslúcida en cuyo interior Plensa coloca una luz.

${ }^{6}$ Añade oportunamente esta autora en el mismo texto estas palabras que precisan el sentido que le da a dicho caos: «el entramado que tejen las letras desordenadas sólo acoge una nada: es como un hálito impregnado de una lengua primordial y silenciosa que no encerraría finalmente otra cosa que un vacío. Algo que es puesto en imagen mediante esta materia escritural caótica de donde todo puede surgir y a donde todo puede regresar» (Von Drathen, 2006: 30).
} 
sentirse. Si fuera posible leer estas esculturas sería a través de una experiencia que aunase todos los sentidos. Pero, ¿es esto posible? ¿Puede leerse un cuerpo cuando ni siquiera los tatuajes que son su piel son legibles? «El me decía que, al ser nosotros mismos un texto enigmático, intentamos, sin éxito, descifrarlo, página a página» (Jabès, 1989: 31). Y es que, como desvela el propio Jabès, debajo de toda palabra se esconde una palabra más esencial, aquélla que el poeta, el creador, busca desesperadamente. Comentando esta idea, se pregunta Jacques Derrida si el libro no sería «la disimulación de una escritura más antigua o más nueva, de otra edad que el libro, que la gramática y que todo lo que se manifiesta ahí bajo el nombre de sentido del ser». Estaríamos así ante una ilegibilidad anterior al libro que sería a la vez «la posibilidad misma del libro, y, en éste, la posibilidad de una oposición, ulterior y eventual, del "racionalismo" y el "irracionalismo"» (Derrida, 1986: 105)7.

Sólo hay un espacio anterior al libro. Es esa escritura ilegible que, sin embargo, está contenida en todo texto. Aquel ámbito, más un espaciamiento que un espacio, es chora. De esta manera, la trayectoria de Plensa puede ser interpretada como una indagación en las posibilidades de representación de algo que es irrepresentable: la medida y el peso del pensamiento, desde las esculturas voluminosas de los años ochenta, de formas geométricas o directamente amorfas, pasando por las piezas en las que escuchamos la vibración de las palabras, hasta llegar a esas figuras humanas hechas de textos, tan abundantes en su última producción. Hay, sin embargo, una constante en todas las series del artista, según él mismo reconoce: la presencia del cuerpo ${ }^{8}$. Quizás en sus trabajos más tempranos, en los que el empleo del hierro, combinado o no con la luz, y de otros materiales dotan a estas piezas de una impronta y de una energía telúricas, lo corporal parecería estar, si no ausente, sí al menos difuminado. Nada de eso. El cuerpo está presente en cuanto 'pensamiento', esto es, como medida y como peso. Posteriormente, conforme el recurso a la escritura se hace más recurrente, el acercamiento hacia lo corporal tiene lugar desde la caligrafía - la de las 'cortinas' - y desde la figura humana — la de los personajes tatuados de sus piezas-. En definitiva, de lo que da testimonio la obra de Plensa es de la identificación entre escritura e imagen, cuerpo y palabra, materia y pensamiento.

Preguntado por la evolución de su trabajo en el periodo 2000-2005, Plensa manifiesta:

Han pasado muchas cosas durante estos cinco años de trabajo, pero la principal ha sido la de poder definir con mayor claridad la estrecha relación del cuerpo humano con el «todo» [...] cuerpo como extensión y representación del mundo y la naturaleza. Esta aproximación al cuerpo es muy parecida a la utilización de textos en mi obra. Un texto está compuesto de palabras y estas palabras a su vez de letras, que como pequeñas células vivas, distintas unas de otras, van creando relaciones hasta formar entes más complejos que a su vez

\footnotetext{
${ }^{7} \mathrm{La}$ anterioridad de esa escritura respecto a la contraposición 'racionalismo' / 'irracionalismo' se corresponde con la caracterización de chora como el espacio previo a toda delimitación, como la de 'sensible' / 'inteligible'. A este respecto señala Derrida lo siguiente: «Khôra recibe, para darles lugar, todas las determinaciones pero ella no posee ninguna propia. Las posee, las tiene - puesto que las recibe-, pero no las posee como propiedades, no posee nada propio. No "es" otra cosa que la suma o el proceso de lo que se inscribe "sobre" ella, a propósito de ella, pero no es el sujeto o soporte presente de todas esas interpretaciones, porque, sin embargo, no se reduce a ellas. Este exceso simplemente no es nada, nada que sea y se diga ontológicamente. Esta ausencia de soporte, que no puede ser traducida en soporte ausente o en ausencia como soporte, provoca y resiste cualquier determinación binaria o dialéctica, cualquier examen de tipo filosófico, digamos, más rigurosamente, de tipo ontológico» (Derrida, 1993: 36-37).

8 «Lo que pasa es que mi obra ha ido transitando por distintos territorios técnicos en función de mis intereses conceptuales. El cuerpo siempre ha sido el lugar común. Ya fuera por referencia, por ausencia o por presencia visual, todo ha girado a su alrededor en esta evolución» (Rendueles, 2007: 44).
} 
se relacionan con otras, y así sucesivamente, expandiéndose sin interrupción. Un cuerpo es muy parecido, formado también por fragmentos inconexos con vida propia que, como contenedores cargados de memoria que pueden actuar separadamente, deciden relacionarse con otros llegando a crear organismos muy complejos (Plensa, 2005: 13).

Llegamos así al final de estas reflexiones propiciadas por la obra escultórica de Plensa, que, creemos, ha encontrado en la escritura como pensamiento la conexión entre el cuerpo humano y ese «todo» que hemos considerado próximo a la noción de chora-caos. Aunque en la última cita este creador emplee una referencia biológica para hablar de su trabajo con las palabras, que vendrían a ser las células del organismo textual, quizás podría recuperarse el enfoque ontológico del que partimos para sostener que lo que todos estos trabajos de la escritura y del cuerpo descubren es la esencia del espacio escultórico. Esta no es, o no sólo, la generación de diferentes lugares a partir de la contemplación de una pieza, sino, ante todo, la dis-posición, el espaciamiento que propicia que haya tales espacios. El empleo de este término remite, como hemos visto, a la chora griega previa a toda distinción y delimitación, incluida la propia diferenciación entre 'espacio' y 'tiempo'. Es muy significativa la frecuencia con la que Plensa insiste en que a él, como escultor, le interesa más el tiempo que el espacio. En realidad escoger entre uno de estos términos carece del sentido. El escultor trabaja con ambos, y si hemos elegido el término «espaciamiento» para traducir esa chora de sus trabajos es porque con él se alude a un acontecimiento - por tanto temporal-, que no cesa de darse, de tener lugar, dando lugar a los espacios que observa, recorre, toca y escucha el espectador. Este ámbito, dominio espacio-temporal si se quiere, es el de una escritura primigenia e ilegible que aguarda recibir una forma. Lo que Plensa persigue, ante todo, es mostrar la forma que tiene previa a esa formalización, si es que algo así es posible. Por eso en ese estado la forma es materia y la materia, forma. Un mundo de caos en el que tal vez podría hallarse la esencia de lo que entendemos por 'espacio'.

\section{Bibliografía}

Blanchot, M. (1955): El espacio literario. Trad. Vicky Palant y Jorge Jinkis. Barcelona, Paidós, 1992.

Buderer, H.-J. (1997): «Jaume Plensa - Réceptacles», en PlensA (1997), pp. 31-33 [la traducción de las referencias a esta obra es nuestra].

DerridA, J. (1986): «Cómo no hablar» y otros textos. Trad. Patricio Peñalver. Barcelona, Anthropos, 1989.

(1993): Khôra. París, Galilée [la traducción de las referencias a esta obra es nuestra].

DuQue, F. (2006): «Sagrada inutilidad (lo sagrado en Heidegger y Hölderlin)», Eikasía. Revista de filosofía, 2, en http://www.revistadefilosofia.org/FelisDuqueMES.pdf (última consulta, 21-062015).

- (2007): «La vibración del ser», en PLENSA (2007), pp. 131-152.

GABILONDO, Á. (2007): «Neutro y singular», en PlENSA (2007), pp. 153-157. 
HeIDEgGer, M. (1969a): Die Kunst und Der Raum / El arte y el espacio. Trad. Jesús Adrián Escudero. Barcelona, Herder, 2009.

- (1969b): Observaciones relativas al arte - la plástica - el espacio / El arte y el espacio. Trad. Mercedes Sarabia. Pamplona, Universidad Pública de Navarra, 2003.

- (1984): Caminos de bosque. Trad. Helena Cortés y Arturo Leyte. Madrid, Alianza, 2008.

JABÈs, E. (1980): Del desierto al libro. Entrevista con Marcel Cohen. Trad. Ana Carrazón Atienza y Carmen Dominique Sánchez. Madrid, Trotta, 2000.

(1989): Un extranjero con, bajo el brazo, un libro de pequeño formato. Trad. Cristina González de Uriarte y Maryse Privat. Barcelona, Galaxia Gutenberg / Círculo de lectores, 2002.

LEYRA, A. M. (2014): ““Chora y Alma del Mundo”. Una mirada metafísica sobre la obra de Chillida», Escritura e Imagen, 10, n ${ }^{\circ}$ ext., pp. 155-173; en http://revistas.ucm.es/index.php/ESIM/article/ view/46925 (última consulta, 19-06-2016).

NANCY, J.-L. (1979): Ego sum. París, Aubier-Flammarion [la traducción de las referencias a esta obra es nuestra].

(1991): Le poids d'une pensée. Montréal-Grenoble, Le Griffon d'Argile - Presses Universitaires de Grenoble [la traducción de las referencias a esta obra es nuestra].

- (1997): Lugares divinos seguido de Cálculo del poeta. Trad. Jordi Massó Castilla y Cristina Rodríguez Marciel. Madrid, Arena Libros, 2014.

Plensa, J. (1997): Jaume Plensa: Fundació Joan Miró, Barcelona 12 desembre 1996 - 9 febrer 1997; Galerie nationale du Jeu de Paume, Paris 24 març - 18 maig 1997; Malmö Konsthall, Malmö 31 maig - 31 agost 1997; Städtische Kunsthalle Mannheim, Mannheim 20 setembre - 9 novembre 1997. Barcelona, Fundació Joan Miró.

(2000): Chaos Saliva. Madrid, Museo Nacional Centro de Arte Reina Sofía.

- (2005): Jaume Plensa: CAC Málaga, Centro de Arte Contempóraneo de Málaga, 7 octubre 2005 - 8 enero 2006 / 7 October 2005 - 8 January 2006. Málaga, Centro de Arte Contemporáneo.

(2006): Jaume Plensa. Une âme, deux corps... trois ombres [8 septembre - 22 octobre 2006]. París, Galerie Lelong. (2007): Sinónimos. Madrid, Círculo de Bellas Artes.

RENDUEles, C. (2007): «Jaume Plensa. La poesía de la materia», Minerva, 5/7, pp. 42-45.

StOEBER, M. (2006): «Transforming Energy. A conversation with Jaume Plensa», Sculpture, 25/2 pp. $38-45$.

VON DRATHEN, D. (2006): «À l'ombre des mots», en PlENSA (2006), pp. 25-30 [la traducción de las referencias a esta obra es nuestra]. 